Revista Tecné, Episteme y Didaxis: TED. Año 2014, Número Extraordinario. ISSN Impreso: 0121-3814, ISSN web: 2323-0126

Memorias, Sexto Congreso Internacional sobre Formación de Profesores de Ciencias. 08 al 10 de octubre de 2014, Bogotá

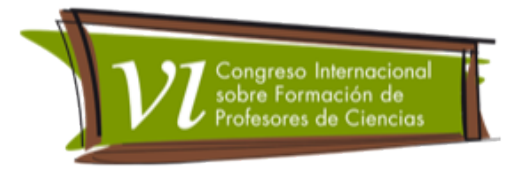

\title{
Algumas Contribuições Da Universidade No Curso De Química: Uma Análise De Duas Realidades Latino- Americanas
}

Santos, Mariana Stegues Marasca', Loguercio, Rochele de Quadros², Salgado, Tania Denise Miskinis ${ }^{3}$

Categoria 2. Trabalho de investigação concluído

\section{Resumo}

Este trabalho analisa comparativamente as ações no âmbito da Universidade Federal do Rio Grande do Sul (Brasil) e da Universidad de la República (Uruguai) que incentivam o aluno a permanecer na graduação e sua colocação no mercado de trabalho durante o curso de Química. Utilizou-se o questionário misto como instrumento de coleta de dados. Evidenciaram-se algumas contribuições que aproximam estas duas realidades, como bolsas de ajuda de custo, auxílio transporte e a moradia estudantil, que são oferecidas por ambas as universidades. Por outro lado, há pontos que as diferenciam: os alunos da UFRGS têm maior incentivo às bolsas de pesquisa e o Restaurante Universitário é aberto a todos os discentes, enquanto que na UDELAR é oferecido apenas àqueles com bolsa alimentação. Diante desse paralelo, discutem-se as possíveis aprendizagens, com base nas ideias de Bourdieu.

\section{Palavras-Chave}

Contribuições da UFRGS e UDELAR. Perfil dos estudantes de Química. Condições de acesso.

\section{Objetivo}

Este trabalho tem por objetivo analisar comparativamente algumas condições que a Universidade Federal do Rio Grande do Sul (Brasil) e a Universidad de la República (Uruguai) oferecem, a fim de facilitar a vida acadêmica e a inserção

\footnotetext{
1 Universidade Federal do Rio Grande do Sul. marianamarasca@terra.com.br

2 Universidade Federal do Rio Grande do Sul. rochelel@gmail.com

3 Universidade Federal do Rio Grande do Sul. tania.salgado@ufrgs.br
} 
Revista Tecné, Episteme y Didaxis: TED. Año 2014, Número Extraordinario. ISSN Impreso: 0121-3814, ISSN web: 2323-0126

Memorias, Sexto Congreso Internacional sobre Formación de Profesores de Ciencias. 08 al 10 de octubre de 2014, Bogotá

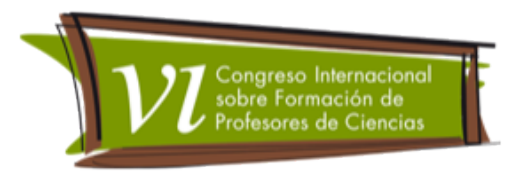

de seus respectivos alunos no mercado de trabalho durante o curso de graduação em Química.

\section{Referencial Teórico}

Para entender esses estudantes em sua realidade educacional utilizou-se como referência os trabalhos de Pierre Bourdieu sobre a possibilidade de ascensão social através do acesso ao conhecimento. O autor identifica três disposições práticas características das famílias de classe média que estão relacionadas imediatamente ao sucesso escolar diferencial dos membros dessa classe. São essas:

(1) o rigorismo ascético, que significa abrir mão de prazeres e confortos imediatos em favor do projeto de ascensão ou manutenção da posição socioeconômica lessa disposição se manifesta, por exemplo, entre estudantes de graduação e pósgraduação que se esforçam em economias, mantendo-se com o valor de suas bolsas de estudo, não por necessidade, mas por opção, como estratégia de se dedicar integralmente aos seus cursos, aumentando suas chances de sucesso no mercado escolar e transformando, posteriormente, seus esforços em conforto e privilégios profissionais); (2) o controle de fecundidade, ou malthusianismo; e (3) a boa vontade cultural, que significa a docilidade e o esforço com que membros dessa classe buscam valorizar, consumir e se apropriar da cultura dominante. (BORDIEU, 2008 apud Lima Júnior; Ostermann; Rezende, 2012, pág. 42).

Para Bourdieu (2004) a realidade social em que o indivíduo está inserido não é feita de ações orientadas pela sua livre consciência individual, ele é um sujeito configurado socialmente, incluindo suas estratégias de convivência no âmbito da escola e suas expectativas com respeito ao futuro profissional. Assim, os indivíduos tenderiam a agir de acordo com o conjunto de disposições práticas típico dos grupos sociais nos quais foram socializados, chamado habitus. Tais disposições não seriam normas inflexíveis, mas princípios gerais que orientam as ações desses sujeitos. Assim, a estrutura social conduziria as ações individuais sem, no entanto, determinar de maneira mecânica e imediata todas as ações dos sujeitos. 
Revista Tecné, Episteme y Didaxis: TED. Año 2014, Número Extraordinario. ISSN Impreso: 0121-3814, ISSN web: 2323-0126

Memorias, Sexto Congreso Internacional sobre Formación de Profesores de Ciencias. 08 al 10 de octubre de 2014, Bogotá

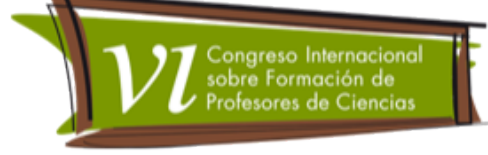

\section{Metodologia}

Esta pesquisa utilizou como principal instrumento de coleta de dados um questionário misto, com questões fechadas e abertas, que se encontra no Apêndice.

Foram aplicados 56 questionários no Uruguai, na Universidad de la República (UDELAR), durante $\circ 1^{\circ}$ semestre de 2012, e 53 questionários no Brasil, na Universidade Federal do Rio Grande do Sul (UFRGS), durante $02^{\circ}$ semestre de 2013. Procurou-se abranger todos os anos cursados na graduação, como mostra ○ Gráfico 1.

Gráfico 1. Número de alunos inquiridos X ano que está cursando.
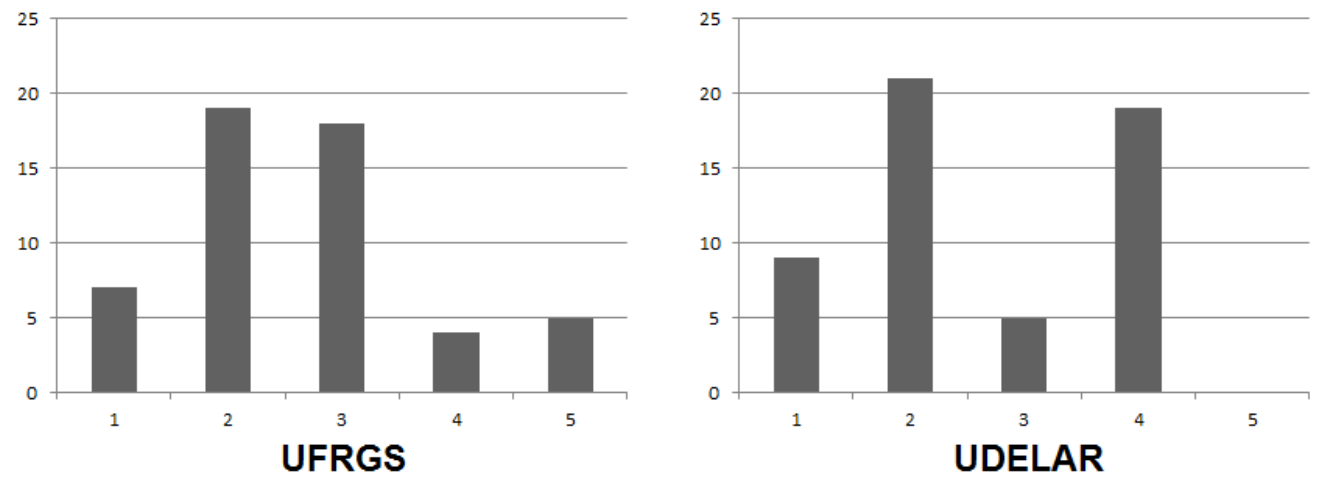

A Faculdade de Química da UDELAR tem as habilitações: Bioquímica Clínica, Química Farmacêutica e Química. O Instituto de Química da UFRGS oferece as habilitações: Bacharelado em Química, Química Industrial e Licenciatura em Química.

\section{Resultados E Discussão}

Esta pesquisa investigou as condições de acesso de ambas as universidades, assim como a informação que os alunos tinham sobre estas contribuições que thes eram oferecidas ou não.

Na UFRGS, a Pró-Reitora de Assuntos Estudantis - PRAE é o órgão que tem a função de tratar dos aspectos relativos à política de atendimento à comunidade discente: 
Revista Tecné, Episteme y Didaxis: TED. Año 2014, Número Extraordinario. ISSN Impreso: 0121-3814, ISSN web: 2323-0126

Memorias, Sexto Congreso Internacional sobre Formación de Profesores de Ciencias. 08 al 10 de octubre de 2014, Bogotá

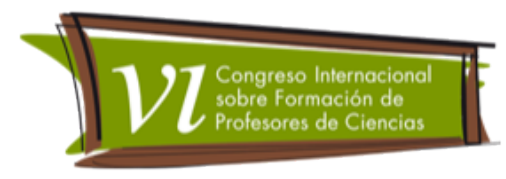

O que move as ações da PRAE é o desenvolvimento de programas e projetos voltados a integrar a comunidade estudantil à vida universitária, contribuindo, através de suas ações, para maior bemestar dos estudantes e pela melhoria de seu desempenho acadêmico, com especial atenção aos de situação financeira insuficiente. A ausência de recursos financeiros cria dificuldades na manutenção desse estudante na Universidade, sendo que, em determinados casos, a desistência ou o retardo da conclusão do curso são fatos comuns no meio acadêmico. Portanto, conjuntamente com a qualidade de ensino ministrada em nossas Universidades Federais, a demanda de uma política de assistência estudantil, englobando o acolhimento desses estudantes, a moradia estudantil, a alimentação, a saúde, a cultura e o lazer são ações a serem perseguidas pela Pró-Reitoria de Assuntos Estudantis durante 0 seu dia-a-dia. (UFRGS, 2013).

Na UDELAR existe a secretaria que trata destas contribuições que a universidade oferece aos estudantes. Além disso, cada faculdade conta com Associações de Estudantes que fiscalizam e administram as becas (chamadas no Brasil de bolsas) que são oferecidas. Dos estudantes da UDELAR, 7,1\% declararam em 2012 que recebiam, ao menos, um tipo de bolsa. A Tabela 1 apresenta a distribuição percentual dos tipos de bolsas recebidas por estes estudantes.

Tabela 1. Porcentagem e tipos de bolsas oferecidas na UDELAR.

\begin{tabular}{|l|l|}
\hline TIPOS DE BOLSA & PORCENTAGEM \\
\hline Bolsa Hospedagem - Beca Hospedaje & 6,1 \\
\hline Bolsa Viagens Interdepartamentais - Beca Viajes interdepartamentales & 16,2 \\
\hline Bolsa Auxílio Alimentação - Beca Alimentaria & 15,8 \\
\hline Bolsa Auxílio Econômico - Beca Económica & 92,6 \\
\hline
\end{tabular}

Fonte: UDELAR - Censo Web 2012.

Nota: Os estudantes podem receber mais de um tipo de bolsa. 
Revista Tecné, Episteme y Didaxis: TED. Año 2014, Número Extraordinario. ISSN Impreso: 0121-3814, ISSN web: 2323-0126

Memorias, Sexto Congreso Internacional sobre Formación de Profesores de Ciencias. 08 al 10 de octubre de 2014, Bogotá

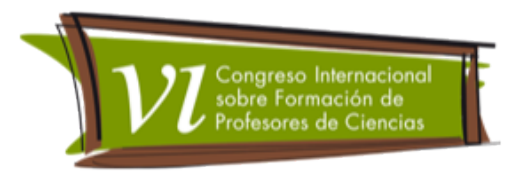

\section{- Ajuda de custo}

A UFRGS tem como método de acolhida a estudantes vindos do interior a Casa do Estudante. São três casas de estudantes, uma em cada campus, bastante concorridas. Cada casa tem seu regimento próprio e seus processos seletivos são diferentes, separados e independentes a cada novo semestre.

A UDELAR disponibiliza bolsas para que os alunos busquem pensões, hostel ou outro tipo de alojamento que mais lhe convier. Porém a UDELAR possui o auxílio de bolsas para viagens interdepartamentais. Este auxílio é bastante útil aos alunos que vivem em departamentos vizinhos e necessitam ir a Montevidéu estudar. Já a UFRGS não disponibiliza ajuda financeira para deslocamento de alunos que moram em outras cidades.

\section{- Restaurantes Universitários}

A UFRGS oferece cinco restaurantes universitários distribuídos nos campi acadêmicos, que funcionam no sistema de "buffet" com variações diárias de cardápios, estabelecidos por nutricionistas. A universidade oferece ainda "Benefício RU" para estudantes de baixa renda comprovada. Para todos os alunos, basta apenas apresentar o cartão UFRGS e pagar o valor de $R \$ 1,30$, já os alunos com o Benefício RU, além de também terem que se identificar, pagam apenas o valor de $R \$ 0,50$.

O Restaurante Universitário da UDELAR destina-se apenas para os estudantes que possuem a Bolsa Auxílio Alimentação (conforme o percentual na Tabela 1), logo, eles não pagam.

De acordo com o Gráfico 2, praticamente 1/3 dos alunos uruguaios não sabem que existe restaurante universitário.

Gráfico 2. Porcentagem de respostas referente à pergunta $n^{\circ} 14$ do questionário, sobre fornecimento de refeições aos estudantes. 
Revista Tecné, Episteme y Didaxis: TED. Año 2014, Número Extraordinario. ISSN Impreso: 0121-3814, ISSN web: 2323-0126

Memorias, Sexto Congreso Internacional sobre Formación de Profesores de Ciencias. 08 al 10 de octubre de 2014, Bogotá
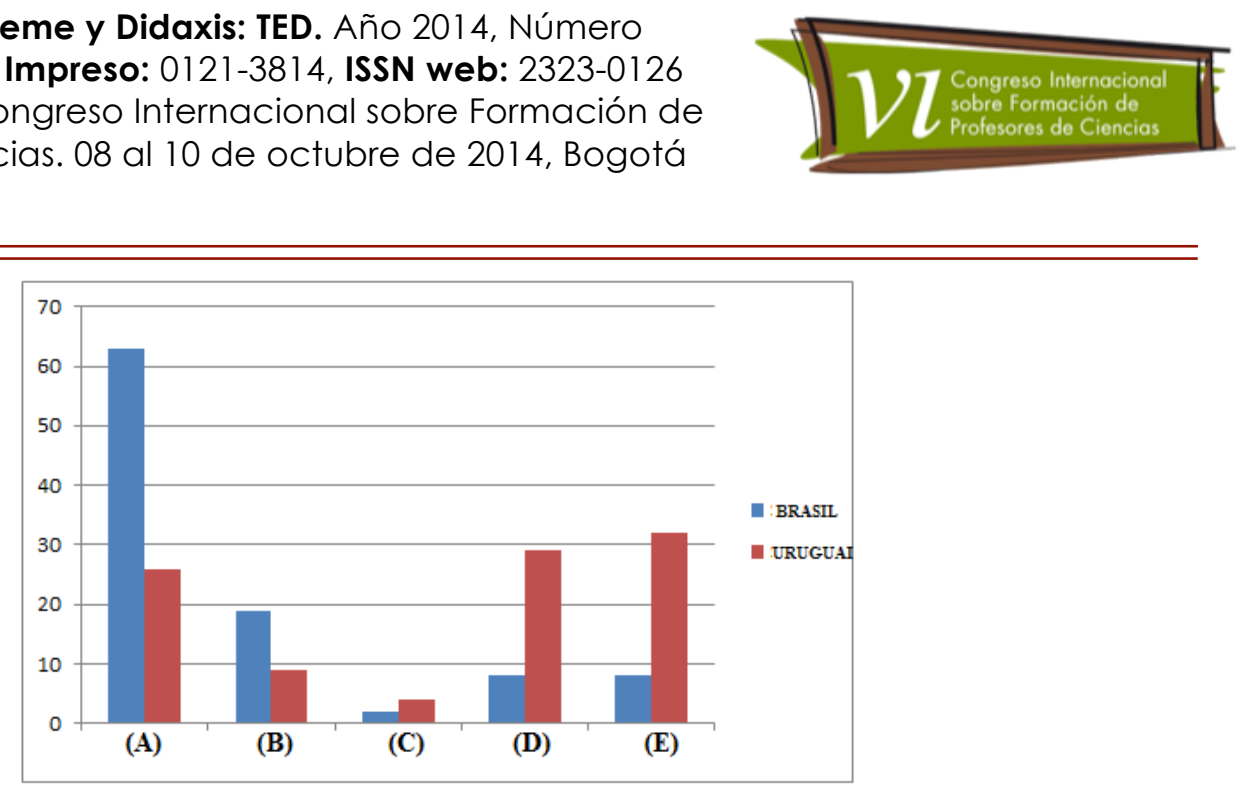

\section{- Bolsa de auxílio econômico}

Ambas as universidades informaram que oferecem bolsas de auxílio econômico a estudantes de baixa renda. Dos estudantes da UDELAR, 7,1\% declararam em 2012 que recebiam, ao menos, um tipo de bolsa. Desses bolsistas, 92,6 \% (conforme Tabela 1) recebiam Bolsa Auxílio Econômico.

Este dado deve ser analisado em conjunto com o Gráfico 3, no qual se verifica que $30 \%$ dos estudantes da UDELAR que responderam ao questionário do presente trabalho não sabem se a universidade oferece este tipo de bolsa e $11 \%$ acredita que sua universidade não as oferece.

Gráfico 3. Porcentagem de respostas referente à pergunta $n^{0} 15$ do questionário, sobre oferecimento de bolsas aos estudantes de baixa renda.

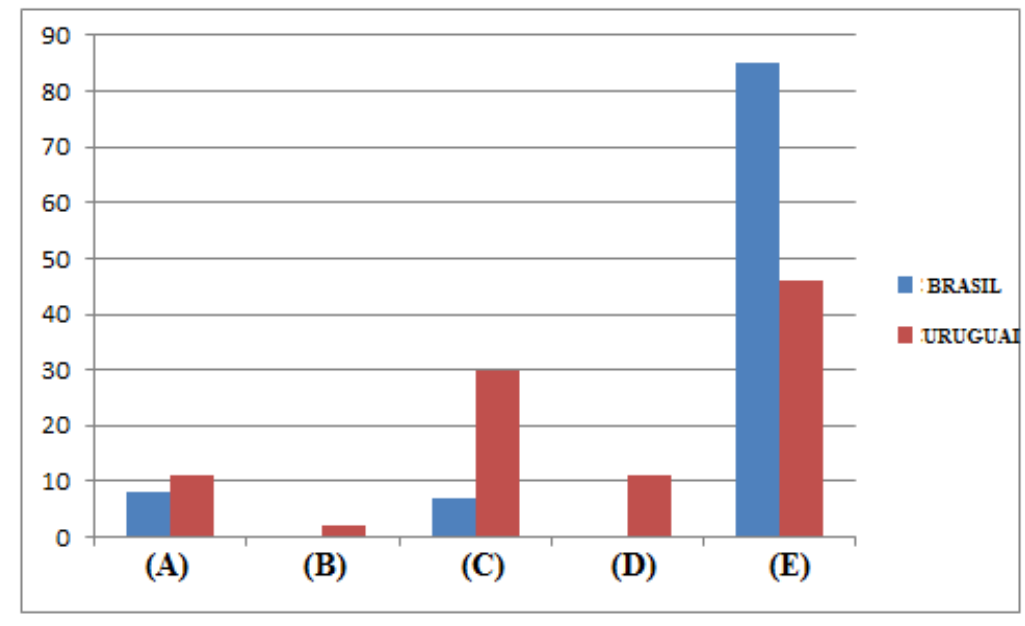


Revista Tecné, Episteme y Didaxis: TED. Año 2014, Número Extraordinario. ISSN Impreso: 0121-3814, ISSN web: 2323-0126

Memorias, Sexto Congreso Internacional sobre Formación de Profesores de Ciencias. 08 al 10 de octubre de 2014, Bogotá

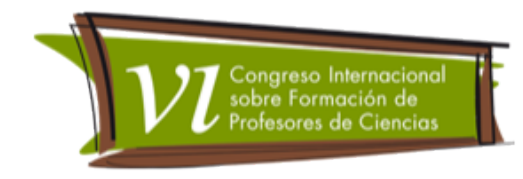

-Porque na UDELAR tantos estudantes desconhecem os auxílios oferecidos? Como está sendo divulgado este benefício aos estudantes?

Durante a pesquisa, as secretarias das duas universidades demonstraram preocupações quanto aos estudantes vindos do interior, porém isso não se refletiu nas respostas dos alunos de ambas as Faculdades de Química. Acredita-se que não basta serem oferecidas melhores condições de acesso, ter um grande investimento em bolsas de alimentação, de auxílio econômico, de transporte, de moradia, se não há plena divulgação de todos estes benefícios. Todos os alunos precisam estar cientes desses benefícios, necessitem deles ou não.

\section{- Bolsas de pesquisa}

Tanto a UDELAR quanto a UFRGS têm oferecido oportunidades de bolsas de pesquisa a seus estudantes. Entretanto, a participação dos estudantes como bolsistas é bastante diferente entre as duas instituições, como mostra o Gráfico 4. Enquanto na UFRGS 65\% dos alunos que responderam o questionário já participou (ou participa) de alguma atividade de pesquisa com bolsa e $6 \%$ foi monitor, na UDELAR a proporção se inverte: apenas $2 \%$ responderam que já tiveram bolsa de pesquisa e nenhum aluno foi tutor/monitor, atingindo-se um percentual de $98 \%$ de alunos que nunca participaram de atividade de pesquisa com bolsa.

Não foi possível obter dados precisos a respeito do número de bolsas de Iniciação Científica disponibilizadas para os estudantes de Química em ambas as universidades, pois nos dois países as respectivas agências de fomento principais (ANII no Uruguai e CNPq no Brasil) concedem as cotas de bolsas diretamente ao pesquisador, o que inviabiliza a contabilização exata do número de bolsas disponíveis nas respectivas unidades acadêmicas. Tanto no Brasil quanto no Uruguai o pesquisador pode ainda receber cotas de bolsas a partir de projetos de pesquisa desenvolvidos em parceria com empresas privadas.

Gráfico 4. Porcentagem de respostas referente à pergunta $n^{\circ} 16$ do questionário, sobre bolsas acadêmicas na universidade. 
Revista Tecné, Episteme y Didaxis: TED. Año 2014, Número Extraordinario. ISSN Impreso: 0121-3814, ISSN web: 2323-0126

Memorias, Sexto Congreso Internacional sobre Formación de Profesores de Ciencias. 08 al 10 de octubre de 2014, Bogotá
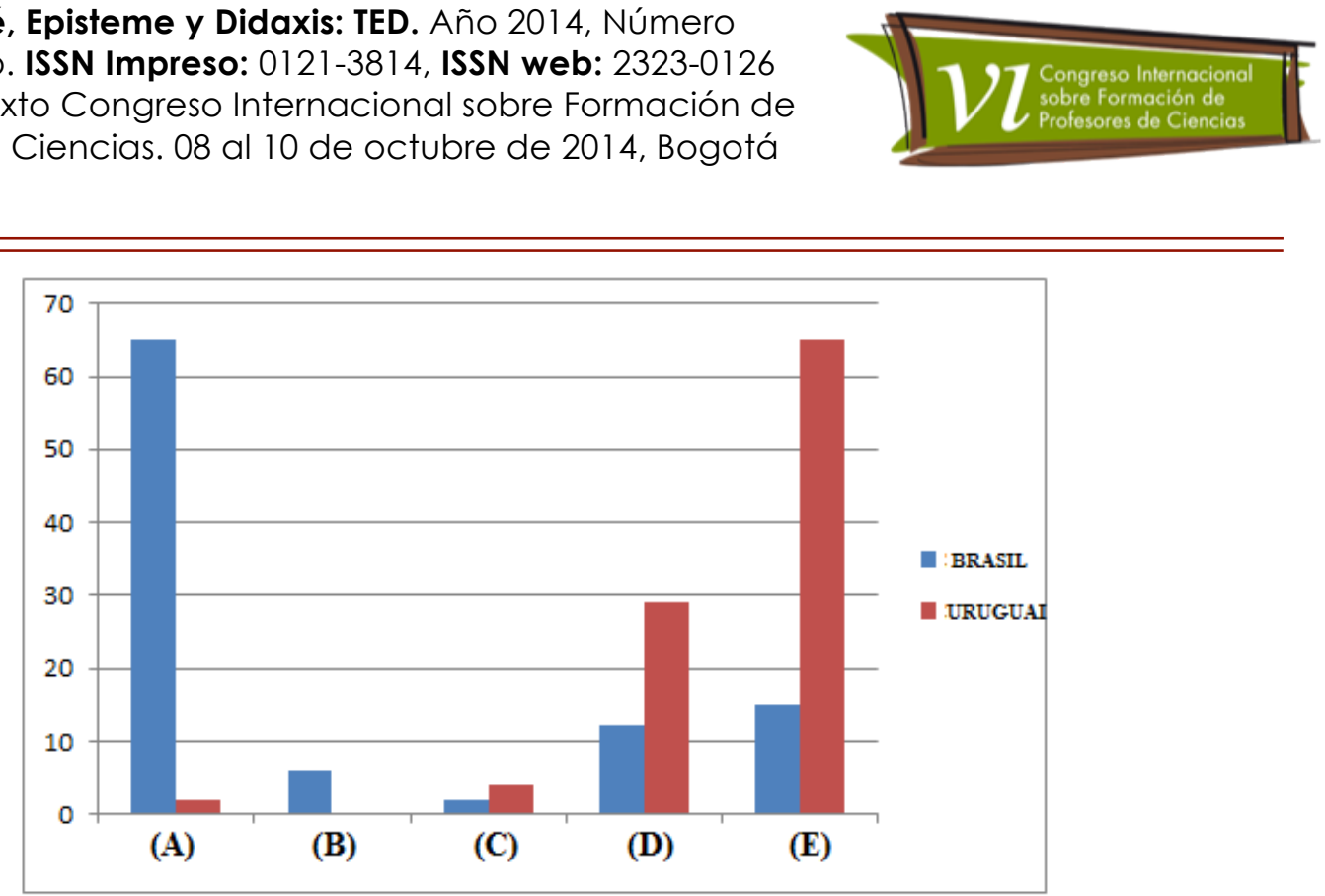

Frente a esses achados da pesquisa, pode-se perguntar o que move os alunos em direção à universidade, especialmente no caso uruguaio?

Na UDELAR é constatado que o egresso não tem dificuldade de se consolidar no mercado de trabalho, então ele opta por ingressar na universidade logo após a saída do Bachillerato. Esses dados corroboram a teoria a respeito das estratégias de investimento escolar proposta por Bourdieu:

Não dispondo de informações suficientemente atualizadas para conhecer a tempo as "apostas" a serem feitas, nem de um capital econômico suficientemente importante para suportar a espera incerta dos ganhos financeiros, nem tampouco de um capital social suficientemente grande para encontrar uma saída alternativa em caso de fracasso, as famílias das classes populares e médias têm todas as chances de fazerem maus investimentos escolares. (NOGUEIRA; CATANI, 2002, pág. 93-94)

Porém Bourdieu também afirma que, dentre estas famílias de classe média, aquelas que vieram de classe popular e devem tudo o que têm ao sucesso escolar dos seus pais e avós, enxergam o exemplo e tendem a traçar estratégias mais agressivas no mercado escolar, ou seja, o aceitam como única alternativa de ascensão social. 
Revista Tecné, Episteme y Didaxis: TED. Año 2014, Número Extraordinario. ISSN Impreso: 0121-3814, ISSN web: 2323-0126

Memorias, Sexto Congreso Internacional sobre Formación de Profesores de Ciencias. 08 al 10 de octubre de 2014, Bogotá

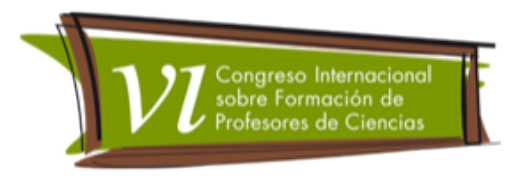

\section{Conclusão}

Diante das reflexões realizadas nesse trabalho, foi possível analisar de acordo com a perspectiva de Bourdieu, algumas condições que são oferecidas pela UFRGS e pela UDELAR a fim de facilitar sua inserção no mercado de trabalho durante a realização de seu curso de graduação. Embora existam e, de acordo com os dados obtidos, sejam de essencial importância para o discente, não são de total conhecimento dos mesmos. Acredita-se que o sentido da universidade proporcionar melhores condições de acesso e permanência seja para que se possa socializar entre todos os que realmente precisam. Para isso, a informação é um direito do aluno e também um dever da universidade.

Conclui-se que as duas realidades analisadas apresentam diferenças, porém convém enxergar que embora o perfil dos estudantes seja distinto, inclusive por causa da própria cultura local, ambas as universidades contribuem para o acesso e permanência de seus estudantes, desempenhando um bom papel na sua formação profissional, visto que ambas são referências no ensino de Química latinoamericano.

\section{Referências bibliográficas}

Bourdieu, P. (2004) Os usos sociais da ciência: por uma sociologia clínica do campo científico. São Paulo: UNESP.

Lima J., P.; Ostermann, F.; Rezende, F. (2012) Análise dos condicionantes sociais da evasão e retenção em cursos de graduação em Física à luz da sociologia de Bourdieu. Revista Brasileira de Pesquisa em Educação e Ciências, São Paulo, v. 12, n. 1, pág. 37-60,. Disponível em <http://revistas.if.usp.br/rbpec/article/viewFile/248/294> Acesso em: 25 nov. 2013.

Nogueira, M. A.; Catani, A (Org.). (2002) Pierre Bourdieu: Escritos de educação. 4. ed. Petrópolis: Vozes,.

Universidade Federal Do Rio Grande Do Sul. Pró-Reitoria De Assuntos Estudantis. Disponível em: <http://www.ufrgs.br/prae/secretaria>. Acesso em: 03 nov. 2013. 
Revista Tecné, Episteme y Didaxis: TED. Año 2014, Número Extraordinario. ISSN Impreso: 0121-3814, ISSN web: 2323-0126

Memorias, Sexto Congreso Internacional sobre Formación de Profesores de Ciencias. 08 al 10 de octubre de 2014, Bogotá

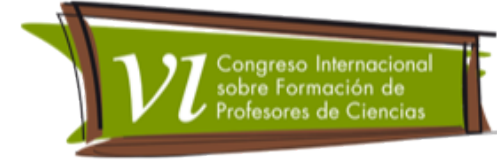


Revista Tecné, Episteme y Didaxis: TED. Año 2014, Número Extraordinario. ISSN Impreso: 0121-3814, ISSN web: 2323-0126

Memorias, Sexto Congreso Internacional sobre Formación de Profesores de Ciencias. 08 al 10 de octubre de 2014, Bogotá

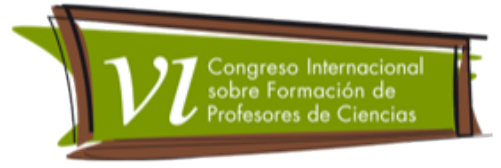

\begin{tabular}{|c|c|}
\hline \multicolumn{2}{|c|}{ Questionário } \\
\hline $\begin{array}{l}\text { 1. Qual o seu sexo? } \\
\text { (A) Feminino. } \\
\text { (B) Masculino. }\end{array}$ & $\begin{array}{l}\text { 2. Qual a sua idade? } \\
\text { (A) } 17 \text { anos ou menos. } \\
\text { (B) } 18 \text { anos. } \\
\text { (C) Entre } 19 \text { e } 25 \text { anos. } \\
\text { (D) Entre } 26 \text { e } 30 \text { anos. } \\
\text { (E) } 30 \text { anos ou mais. }\end{array}$ \\
\hline $\begin{array}{l}\text { 3. Onde e como você mora atualmente? } \\
\text { (A) Em casa ou apartamento, com minha } \\
\text { família. } \\
\text { (B) Em casa ou apartamento, sozinho (a). } \\
\text { (C) Em quarto ou cômodo alugado, sozinho } \\
\text { (a). } \\
\text { (D) Em habitação coletiva: hotel, hospedaria, } \\
\text { quartel, pensionato, república etc. } \\
\text { (E) Em habitação coletiva durante a semana, } \\
\text { mas aos fins de semana vou para a casa da } \\
\text { minha família. }\end{array}$ & $\begin{array}{l}\text { 4. Quanto tempo voce gasta para chegar até a } \\
\text { faculdade? } \\
\text { (A) Pouco tempo porque moro perto. } \\
\text { (B) Menos de } 30 \text { minutos por dia. } \\
\text { (C) Entre } 30 \text { minutos e } 1 \text { hora por dia. } \\
\text { (D) Mais de uma hora por dia. } \\
\text { (E) Mais de duas horas por dia. }\end{array}$ \\
\hline $\begin{array}{l}\text { 5. Você acredita que o seu tempo de } \\
\text { deslocamento (ida e volta entre a faculdade e } \\
\text { a sua residência) atrapalha o seu rendimento } \\
\text { acadêmico? } \\
\text { (A) Não, porque moro perto. } \\
\text { (B) Não, porque utilizo este tempo para } \\
\text { estudar. } \\
\text { (C) Sim, porque moro longe, perco muito } \\
\text { tempo no deslocamento. } \\
\text { (D) Sim, por este motivo falto muitas aulas. } \\
\text { (E) Sim, fico muito cansado e não consigo } \\
\text { prestar atenção às aulas. }\end{array}$ & $\begin{array}{l}\text { 6. Com que idade voce entrou na faculdade? } \\
\text { (A) } 17 \text { anos ou menos. } \\
\text { (B) } 18 \text { anos. } \\
\text { (C) Entre } 19 \text { e } 25 \text { anos. } \\
\text { (D) Entre } 26 \text { e } 30 \text { anos. } \\
\text { (E) } 30 \text { anos ou mais. }\end{array}$ \\
\hline $\begin{array}{l}\text { 7. Você trabalha ou já trabalhou ganhando } \\
\text { algum salário? } \\
\text { (A) Trabalho, estou empregado com carteira } \\
\text { de trabalho assinada. } \\
\text { (B) Trabalho, mas não tenho carteira de } \\
\text { trabalho assinada. } \\
\text { (C) Trabalho por conta própria, não tenho } \\
\text { carteira de trabalho assinada. } \\
\text { (D) Já trabalhei, mas não estou trabalhando. } \\
\text { (E) Nunca trabalhei. }\end{array}$ & $\begin{array}{l}\text { 8. Voce trabalha ou já trabalhou em alguma } \\
\text { atividade remunerada durante seus estudos } \\
\text { academicos? } \\
\text { (A) Sim, todo o tempo. } \\
\text { (B) Sim, de } 1 \text { a } 2 \text { anos. } \\
\text { (C) Sim, de } 2 \text { a } 3 \text { anos. } \\
\text { (D) Sim, mais de } 3 \text { anos. } \\
\text { (E) Não. }\end{array}$ \\
\hline
\end{tabular}


Revista Tecné, Episteme y Didaxis: TED. Año 2014, Número Extraordinario. ISSN Impreso: 0121-3814, ISSN web: 2323-0126

Memorias, Sexto Congreso Internacional sobre Formación de Profesores de Ciencias. 08 al 10 de octubre de 2014, Bogotá

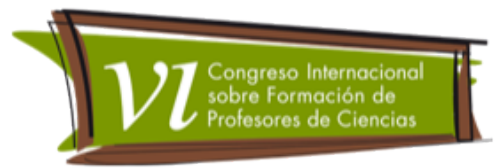

\begin{tabular}{|c|c|}
\hline $\begin{array}{l}\text { 9. Com que finalidade voce trabalha ou } \\
\text { trabalhava enquanto estuda? } \\
\text { (A) Para ajudar meus pais nas despesas da } \\
\text { família. } \\
\text { (B) Para sustentar a minha família (esposo/a, } \\
\text { filhos/as etc.) } \\
\text { (C) Para gastos pessoais (buscar } \\
\text { independencia financeira). } \\
\text { (D) Para adquirir experiencia. } \\
\text { (E) Nunca trabalhei enquanto estudo. }\end{array}$ & $\begin{array}{l}\text { 10. Como voce avalia estudar e trabalhar, } \\
\text { simultaneamente, durante a faculdade? } \\
\text { (A) Atrapalha meus estudos. } \\
\text { (B) Possibilita meu crescimento pessoal. } \\
\text { (C) Atrapalha meus estudos, mas possibilita meu } \\
\text { crescimento pessoal. } \\
\text { (D) Não atrapalha meus estudos. } \\
\text { (E) Nunca trabalhei enquanto estudo. }\end{array}$ \\
\hline $\begin{array}{l}\text { 11. A faculdade que voce frequenta leva em } \\
\text { conta que voce trabalha ao mesmo tempo em } \\
\text { que estuda? } \\
\text { (A) Sim. } \\
\text { (B) Não, nunca me perguntaram sobre isso. } \\
\text { (C) Não, mas já me perguntaram se eu } \\
\text { trabalho. } \\
\text { (D) Não sei. } \\
\text { (E) Eu não trabalho. }\end{array}$ & $\begin{array}{l}\text { 12. A faculdade oferece horários flexíveis aos } \\
\text { alunos que trabalham? } \\
\text { (A) Sim, oferece aulas à noite ou em fins de } \\
\text { semana. } \\
\text { (B) Sim, mas eu não necessito, pois peço folga no } \\
\text { trabalho para frequentar o horário regular. } \\
\text { (C) Não, os horários são fixos. } \\
\text { (D) Não sei. } \\
\text { (E) Eu não trabalho. }\end{array}$ \\
\hline
\end{tabular}

13. A faculdade tem algum programa de estudos extraclasse ou de recuperação de notas para alunos que trabalham?

(A) Sim, oferecem aulas extras e abonam algumas faltas.

(B) Sim, mas eu não utilizo.

(C) Não há nenhum programa.

(D) Não sei.

(E) Eu não trabalho.

14. A faculdade fornece refeição aos estudantes?

(A) Sim, eu utilizo.

(B) Sim, mas não utilizo porque não gosto.

(C) Sim, mas não utilizo porque é muito longe.

(D) Não fornece.

(E) Não sei.

15. Você desfruta de algum auxílio em dinheiro que a faculdade oferece aos estudantes de baixa renda?

(A) Sim, recebo uma bolsa.

(B) Sim, recebo meia bolsa.

(C) Não sei se minha faculdade oferece.

(D) Minha faculdade não oferece bolsas.

(E) Minha faculdade oferece bolsas, mas eu nõo recebo.

16- Você já participou de alguma atividade remunerada na faculdade?

(A) Sim, trabalhei em atividades de pesquisa.

(B) Sim, fui tutor/monitor em algumas disciplinas.

(C) Não, mas participei de atividades nõo remuneradas.

(D) Não, porque não tenho interesse em trabalhar na faculdade.

(E) Não, porque nunca tive a oportunidade. 
Revista Tecné, Episteme y Didaxis: TED. Año 2014, Número Extraordinario. ISSN Impreso: 0121-3814, ISSN web: 2323-0126

Memorias, Sexto Congreso Internacional sobre Formación de Profesores de Ciencias. 08 al 10 de octubre de 2014, Bogotá

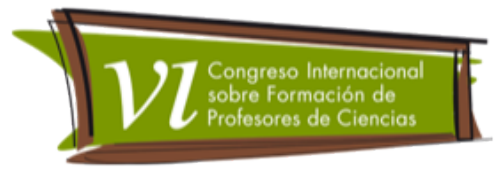

\begin{tabular}{|c|c|}
\hline $\begin{array}{l}\text { 17- Você conhece algum colega de curso que } \\
\text { desistiu? } \\
\text { (A) Sim, conheço } 1 \text { colega. } \\
\text { (B) Sim, conheço } 2 \text { colegas. } \\
\text { (C) Sim, conheço } 3 \text { colegas. } \\
\text { (D) Sim, conheço mais de } 3 \text { colegas. } \\
\text { (E) Não, nõo conheço nenhum colega que } \\
\text { desistiu. }\end{array}$ & $\begin{array}{l}\text { 18- Você sabe o motivo que seus colegas de } \\
\text { curso desistiram? } \\
\text { (A) Não conheço nenhum colega que desistiu. } \\
\text { (B) Não sei os motivos da desistência. } \\
\text { (C) Sim, as matérias são muito difíceis. } \\
\text { (D) Sim, a faculdade era muito longe de sua } \\
\text { casa. } \\
\text { (E) Sim. Outros: }\end{array}$ \\
\hline $\begin{array}{l}\text { 19. Nome do curso: } \\
\text { Semestre em curso: }\end{array}$ & 20. Desde quando voce optou por este curso? \\
\hline 21. Porque voce escolheu este curso? & $\begin{array}{l}\text { 22. Levando em conta o que voce estudou até } \\
\text { hoje, o curso que voce escolheu correspondeu } \\
\text { às suas expectativas? }\end{array}$ \\
\hline $\begin{array}{l}\text { 23. Voce aconselharia algum outro jovem a } \\
\text { fazer este curso? Por que? }\end{array}$ & $\begin{array}{l}\text { 24. Você pensa em algum dia ser professor? Por } \\
\text { que? }\end{array}$ \\
\hline $\begin{array}{l}\text { E-mail opcional para contato: (para receber or } \\
\text { desta pesquisa) }\end{array}$ & esultado resumido ou a tabulação do questionário \\
\hline
\end{tabular}

